\title{
A Conceptual Review on Using Consequential Life Cycle Assessment Methodology for the Energy Sector
}

\author{
Quyen Le Luu, Sonia Longo*(D), Maurizio Cellura, Eleonora Riva Sanseverino, \\ Maria Anna Cusenza and Vincenzo Franzitta $\mathbb{D}$ \\ Dipartimento di Ingegneria, Università degli Studi di Palermo, Viale delle Scienze Ed.9, 90128 Palermo, Italy; \\ lequyen.luu@unipa.it (Q.L.L.); maurizio.cellura@unipa.it (M.C.); eleonora.rivasanseverino@unipa.it (E.R.S.); \\ mariaanna.cusenza@unipa.it (M.A.C.); vincenzo.franzitta@unipa.it (V.F.) \\ * Correspondence: sonia.longo@unipa.it
}

Received: 20 May 2020; Accepted: 12 June 2020; Published: 14 June 2020

\begin{abstract}
Energy is engaged in the supply chain of many economic sectors; therefore, the environmental impacts of the energy sector are indirectly linked to those of other sectors. Consequential life cycle assessment (CLCA) is an appropriate methodology to examine the direct and indirect environmental impacts of a product due to technological, economic or social changes. To date, different methodological approaches are proposed, combining economic and environmental models. This paper reviews the basic concept of CLCA and the coupling of economic and environmental models for performing CLCA in the energy sector during the period 2006-2020, with the aim to provide a description of the different tools, highlighting their strengths and limitations. From the review, it emerges that economic modelling tools are frequently used in combination with environmental data for CLCA in the energy sector, including equilibrium, input-output, and dynamic models. Out of these, the equilibrium model is the most widely used, showing some strengths in availability of data and energy system modelling tools. The input-output model allows for describing both direct and indirect effects due to changes in the energy sector, by using publicly available data. The dynamic model is less frequently applied due to its limitation in availability of data and modelling tools, but has recently attracted more attention due to the ability in modelling quantitative and qualitative indicators of sustainability.
\end{abstract}

Keywords: consequential life cycle assessment (CLCA) concept; economic and environmental model; energy sector

\section{Introduction}

Greenhouse gas (GHG) emissions from the energy sector are considered as a hot spot at the national and global scale due to their large share of the total emissions. According to the European Environment Agency, energy production and consumption contributed to $76 \%$ of the EU-28 and Iceland's GHG emissions [1]. Meanwhile, energy is engaged in the supply chain of economic sectors, as the economic sectors in society require energy to produce their added values. Therefore, any increase in energy demand for different economic sectors will induce changes in the energy sector and its GHG emissions, and vice versa.

Life cycle assessment (LCA) is a holistic approach to quantify potential environmental impacts of a product system throughout its life cycle [2], with two main variants: Attributional and consequential LCA (CLCA). While the attributional LCA (ALCA) quantifies the physical inflows and outflows directly related to the product system, without considering the effects that it can generate on other economic sectors, the CLCA expands the system boundaries by including the marginal or avoided impacts induced by a change in the product system on other economic sectors. The product system 
can be considered as a "partial process" that overlaps and influences other processes [3]. New spatial and temporal boundaries of the product system must be defined in CLCA, according to the goal of the analysis.

CLCA accounts for both environmental impacts during the supply chain of the product system, as well as the impacts originated from changes of the examined system in other economic sectors, which are implied as direct and indirect environmental impacts in this paper, respectively. In the energy sector, the consequential approach is highly important due to the fact that it interacts with most economic sectors in society. In this paper, the term "economic sectors" denotes system of national accounts economic (production) sectors, which are described in monetary and economic flows [4].

Originally, CLCA was defined as aiming "at describing the effects of changes within the life cycle" [5]. Similarly, other authors defined CLCA as "an approach describing how the environmentally relevant physical flows to and from the technological system will change in response to possible changes in the life cycle" [6] or "an approach to estimate how flows to and from the environment will change as a result of different potential decisions" [7]. CLCA is usually based on a quantitative analysis and this can represent a limit of the methodology, considering that economic growth involves not only quantitative changes but also qualitative transformations, as suggested by Georgescu-Rogen [8]. This aspect should be further integrated in future CLCA studies or in any case, a trade-off between CLCA outcomes and other qualitative aspects should be integrated in multi attribute decision making processes.

Soimakallio et al., who agreed with [5], defined CLCA as a method for describing potential changes in environmental impacts of a product system in response to possible decisions that would have been or will be made [9]. These definitions focus on the causal relationship of CLCA approach which occurs during different processes over the product system's life cycle, and it is not clear on the nature of the change, i.e., whether the change occurs due to a technological improvement during the supply chain of the product system or it originates from increased demand of the product or of relevant co-products.

The changes in product system and its environmental impacts may occur within its own boundary. These changes may be physical changes of the product system, for example, change in the carbon stock of land used for bioenergy will induce change in bioenergy GHG emissions. Other examples, such as change in the solar radiation (nature) or wind generator efficiency (equipment), which induce change in the output of the renewable energy systems, consequently change the environmental impacts of the systems. At this point, the consequential approach quantifies the environmental impacts by taking the absolute value of the impacts of the studied product system after and before change, without the need to consider the product system under the linkage with other economic sectors.

It should be noted that this concept does not at all ignore the circularity effect of conventional LCA, in which (partial) outputs of one process are inputs for others. A simple example follows: To generate fossil fuel based power, we need minerals or fuels such as coal or natural gas. In turn, we need power (energy) to mine coal or to exploit natural gas. This creates a loop of physical inputs and outputs over the product system's life cycle. On one hand, this loop results in a circulation of energy and material inside the product system boundary, and at the end of the day, it raises a question of net energy and material output [8]. On the other hand, we must not forget the role of other inputs contributing to a product system other than environmentally physical ones. These include socio-economic inputs such as capital and labor [8]. As a consequence, it returns to the importance of identifying the system boundary of a CLCA [3].

In any case, still now the establishment of the boundary is one of the most debated questions of CLCA. However, including or excluding some processes is sometimes done inconsistently, using different arguments, which leads to different results.

Some authors extended the definition of CLCA to include the environmental impacts on other sectors due to market related changes. For example, Nielsen et al. assessed the environmental impacts of the product system in which "environmental profiles are compiled by addressing changes induced by a change in demand for the company's products" [10]. Earles and Halog defined CLCA as "an 
emerged modelling approach for capturing environmental impacts of product systems beyond physical relationships accounted for in ALCA" [11]. Earlier, Georgescu-Rogen mentioned the solution for including impacts of economic activities and the energy- material flows by considering the energy sector under a set of economic processes instead of a thermodynamic flow [12] and proposed the passing to the multi process matrix to better cover several socio-economic indicators which are unavailable in the input-output matrix [13].

These authors agreed on the economic relations between the studied product system and other economic sectors, therefore, there will be indirect environmental impacts due to a change in the studied product system on other relevant product systems and vice versa. As an example: the EU bioenergy policy requires the bioethanol consumption by 2030, which causes an increasing demand of this product system in the same timeframe. In order to meet that demand, bioethanol exporters to EU market, e.g., from Malaysia, have to produce more bioethanol. This will require more inputs (land, seeds, fertilizers, etc.) in Malaysia to grow energy crops. At the same time, the amount of co-products of the bioethanol production process, e.g., animal feeds, will increase. As a consequence, the environmental impacts of the bioethanol product system will now equal to the direct impacts of bioethanol, adding indirect impacts from increased bioenergy production in Malaysia, subtracting indirect impacts from reduced animal feeds being substituted by Malaysian animal feeds.

The coupling of environmental and economic metrics has been studied for a long time. It started with the effort of linking demand on energy sources and economic activity [14]. The consumed resources were vast in terms of natural resources, such as copper in Leontief cited in [14], nitrogen in Herendeen cited in [14] or social resources such as labor in Bezdel and Hannon cited in [14]. These resources were initially focused on their embodied energy [14] and were later broadened into energy and material, for example raw materials equivalents tools and the database of Eurostat [15], and the System of Environmental Economic Accounting database of the United Nations [16]. This coupling quantified the energy and material used for the product or service itself, as well as those used in the background processes during the production of that product or service.

However, there are risks on mixing different approaches based on physical valuation, e.g., energy analysis, material flow analysis, and economic valuation, for example double counting [8], combining different metrics [8] and uncertainty due to transformation of energy [14]. The proposed solution for this analysis was to use a processed based matrix composed of both economic and physical inputs and outputs [8]. In other words, the transformation of pure economic input-output methodology or pure (physical) energy and material analysis methodology to get the best of both worlds.

In this paper, we follow the latter notion of CLCA, in which environmental profile of the product system includes both direct and indirect impacts, originating from the change in the product system life cycle, while interacting with other aspects of the economy and society. In order to fully assess these indirect impacts, it is necessary to include economic modelling in CLCA. This paper will review the current state-of-the-art of CLCA studies in the energy sector. It will focus on the combination of economic and environmental models for performing CLCA in the energy sector, with the aim to provide a description of the different tools used, highlighting their strengths and limitations.

\section{Methodology}

The systematic review was conducted using a 5 step approach, as follows: Develop research questions; find relevant studies; appraise quality and extract data; synthesize and interpret [17]. The research question is as follows: 'If something changes in the energy sector, what are the tools for modelling both the direct and indirect environmental effects?' The literature search was then conducted on Web of Science and Science Direct using CLCA and energy sector as the search terms. Other variants of CLCA such as 'dynamic', 'change' and 'causal' have also been searched for, by using the algorithm of CLCA OR dynamic OR change OR causal AND energy sector. The initial results included 221 papers on CLCA papers related to energy. These papers were primarily screened through the titles and abstracts to exclude those that were relevant to food energy, or that considered energy as a 
medium during the production line, instead of the product system. At the end of the primary screening, there were 118 papers including both methodology papers and case studies. These 118 papers went through the secondary screening for their general application such as geographical coverage, temporal horizon and use of economic modelling. At the end of the secondary screening, there were 43 case studies using applied economic models in combination with LCA. These papers were quoted and specifically reviewed for their applications of economic models and LCA.

\section{Results and Discussion}

\subsection{Application of CLCA in the Energy Sector}

The initial review includes 118 papers published from 2006 to 2020 on three topics: Bioenergy, power and other. The numbers of papers by year and topic are presented in Figure 1. Research on CLCA was scarcely conducted before 2010. The number of papers has increased steadily since 2011 and peaked in 2017. Papers on the topic of 'bioenergy' accounted for $56 \%$ of the total number of papers. This may originate from the interrelation of bioenergy and other sectors such as agriculture in terms of land use change, and transportation in terms of globally scaled geographical lines of biofuels, and social controversy between the 1st and 2nd generation of biofuels. The number of studies on the topic 'power', which include papers on electric power of all types, was very little in the first half of the research period, but has recently increased, with six papers in 2019. This can be explained by the change in the power system, with the integration of renewable power such as wind and solar, and consequently energy storage systems, which require the need of a CLCA approach to model environmental impacts in relation with power system changes. Papers on topics of 'other' account for a small number of total papers (20/118 papers). These cover different product systems such as fuel cell bus, hydrogen, electric vehicles (not to be used for vehicle-to-grid applications), heat, fossil fuels.

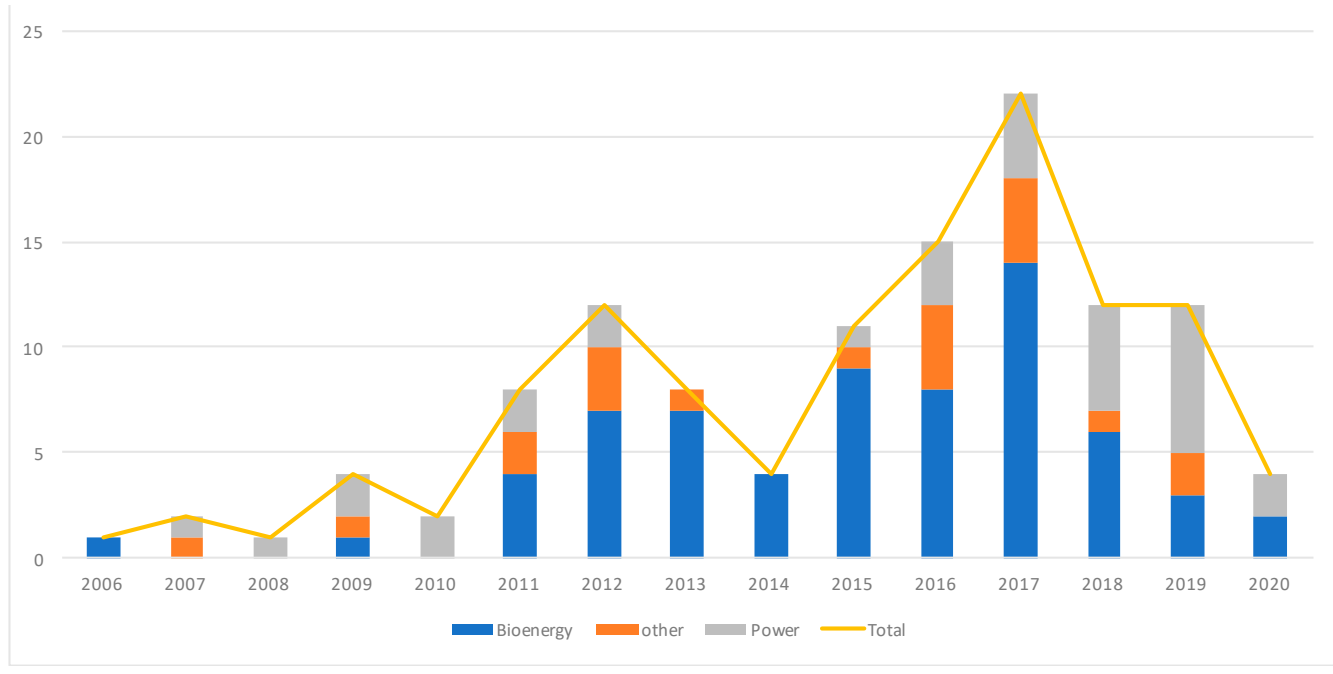

Figure 1. Numbers of articles by years and topics.

There is a large difference in geographical coverage of CLCA studies. Out of 102 case studies, 74 were conducted within the EU and UK boundary, this accounts for up to $73 \%$ of studies. Meanwhile, only a small number of studies were conducted elsewhere around the world, in Asia (11), America (8), Australia and New Zealand (2) and Africa (1). Interestingly, 5 studies were conducted at the global scale, which try to identify the global marginal energy mix, for example global nuclear power development [18], global electric mix [19], global low carbon electricity [20], global biofuel transport [21] and long term marginal electricity mix of 40 countries [22]. 
In term of temporal horizon, two papers [23,24] out of 102 case studies modelled the change in the past through a survey and monitoring program. Specifically, Hou et al. conducted a monitoring project and a questionnaire survey on biogas consumption and leakage and digestate quantities for the two villages in China [23]. Data in the study were obtained in 2010 to calculate the GHG balance and in 2014 to evaluate changes in rural household biogas systems [23]. Meanwhile, Moore et al. carried out an analysis of various scenarios with two control variables: Crop management techniques and source of nutrients for sugarcane crops to examine the effects of replacing chemical fertilizers with vinasse and filter cake during ethanol production [24]. These scenarios were developed for the period of 2011-2015, and the changes were quantified based on a substitution approach, through screening governmental documents and literature [24].

There were several papers ( $23 \%$ of the total case studies in the review) which did not clarify the studied timeframe. The change in the physical or biophysical flow of the product system, for example changes in soil organic carbon [25,26], or in protein feed [27], is considered relatively constant over time. Furthermore, most of them did not apply any economic model, except for one study using system dynamics.

The remaining papers studied the change in the product system for short or medium to long term. The short timeframe is every $30 \mathrm{~min}$, hourly or monthly, and this was applied in 5 studies [19,28-31] which were recently conducted on power/heat generation systems. For medium to long term timeframe, there were 56 papers, accounting for $55 \%$ of the reviewed case studies, ranging from 3 to 21 years of cycle crop or lifecycle of the product system [32-36] to 10, 20, 30, or 40 years. The studied timeframe ranged up to 200 years of forecasting scenarios, with product system of a $6 \mathrm{MW}$ bio heat plant in UK [37].

Out of 102 case studies, 59 did not apply any economic modelling. They conducted a CLCA by developing different scenarios taken from governmental reports and plans, and identified marginal/ affected technologies based on change in carbon flows or reviewing historical LCA studies, journal papers and published plans with results of economic model simulations. As this systematic review concentrates on the combination of economic and environmental models for performing CLCA, these papers have been excluded.

The remaining 43 papers, which are the main focus of the review, applied one or several economic models, in combination with LCA to model the indirect environmental changes. An example of coupling economic models and LCA is presented in Figure 2. Among papers that coupled economic models and LCA, the most frequently applied approaches included partial equilibrium model (PEM), general equilibrium (GE), input-output (IO), agent based modelling (ABM) and system dynamic (SD) models. A third of the papers used several models in combination, i.e., concurrently applying PEM $+\mathrm{GE}$, or PEM + IO, or GE + IO. The application of a dynamic model such as ABM and SD is less common than equilibrium and IO models. 


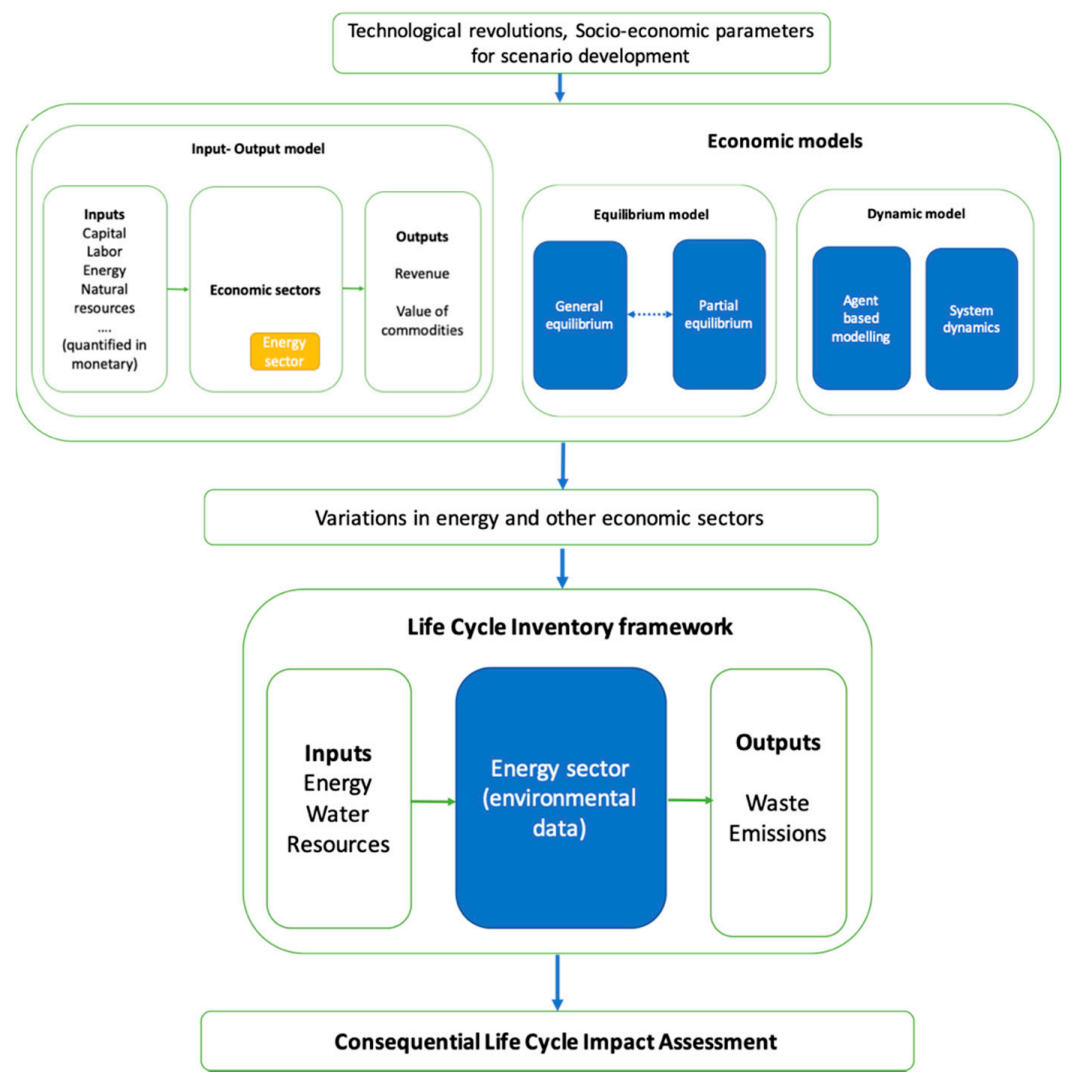

Figure 2. Economic models and Life cycle assessment (LCA) for consequential LCA (adapted from [38]).

\subsection{Partial Equilibrium Model}

\subsubsection{Conceptual Model}

The PEM explains the behavior of supply and demand of the product system as one part of the economy. The product systems, which are considered with PEM, can be any product of the economic activities and is not limited in the energy sector. This economic model focuses on the primary relations of supply, demand and price of the product system, and considers the product system and being partial closed to other economic sectors, i.e., the impacts of other economic sectors on the product system can be linked by changing parameters and variable exogenously [39].

This type of model analyzes the immediate or primary effects of economic disturbance, or the possible effects of a policy on one or several markets, in which any change in price will induce change in supply and demand of the product system. There are three endogenous variables in the PEM: supply, demand and price, which are determined by the solution of the model (see Equations (1)-(3) for a simple PEM). There are also several coefficients or parameters to reflect the reactions of demand and supply to the price. Depending on the specific PEM modelling tools, there are several exogenous parameters such as gross domestic product (GDP), inflation, population growth, price of input material, investment capital for technology, etc., which impact either supply or demand. The equilibrium price solution of the model can be obtained through setting demand equal to supply.

The mathematical equations for PE are presented as follows:

$$
\begin{gathered}
Q_{d}=Q_{s} \\
Q_{d}=a-b P \\
Q_{s}=c P-d
\end{gathered}
$$

in which: 
$Q_{d}$ is the demanded quantity of the commodity;

$Q_{s}$ is the supplied quantity of the commodity;

$P$ is the price of commodity.

$a, b, c, d$ are fixed or exogenous coefficients/parameters, which can be altered depending on the specific PE modelling tool, for example GDP, population growth, price of input material, or investment capital for technology.

\subsubsection{Operational Model}

The PEM has been coupled with LCA to estimate indirect environmental impacts originating from market force [40]. For example, Bouman et al. cited in [11] examined the effectiveness of several tax instruments on reducing the amount of mined, landfilled, and emitted lead from batteries. Ekvall and Andrae cited in [11] explored the impacts of lead solder ban in the electronics industry. Earles et al. analyzed energy demand scenarios in the case that more wood is used for ethanol production [41]. Vázquez-Rowe et al. assessed environmental changes in the agricultural sector in Luxembourg linked to an expected increase in maize cultivation for energy generation [39].

Due to the fact that the PEM considers the product system without connection to the rest of the economy, the coupling of PEM and LCA is frequently applied to an industry or an economic sector [42]. Several authors clarified that the PEM and LCA coupling is suitable to study one or two closely related sectors with 5 to 20 products $[43,44]$. This is true for all reviewed case studies which applied PEM and LCA, with focus on one sector of energy production [22,29-31,44-51], or two sectors of energy production and waste management $[52,53]$ or energy production and agriculture/forest/crop growing [39,41,54-62].

The coupling of PEM and LCA is mostly applied at macro geographic areas. Most of the reviewed PEM and LCA case studies (19 out of 24) were conducted at the national level. There are four case studies using PEM and LCA at the regional scale, e.g., expanding the geographical boundary to several countries by including import and export. Katelhon et al. and Beaussier et al., who agreed with this point, identified that the geographical boundary of PEM ranges from the macro to meso scale [42,43]. Interestingly, one case study used PEM and LCA at the global level to identify the long-term marginal electricity supply mixes of 40 countries in the period of 2015-2030 [22].

The coupling of PEM and LCA can run in various time horizons, either very short or medium, and long term. For the very short term, PE-LCA was applied to identify the impacts of marginal energy production and consumption hourly, monthly or even every $30 \mathrm{~min}$ [29-31]. The medium and long terms are common among the reviewed case studies, with up to 20 papers conducting a CLCA over a time frame of 15 to 20 years, and one paper with the time frame of 40 years.

The high percentage of coupling PE and LCA in the energy sector among reviewed case studies indicated that it seems to be the most common tool. This may originate from the availability of energy system modelling tools, which are mostly based on PE principles, such as NELSON, E2M2, Euroelectric, Energy 2020, ETM-UCL, Balmore, TIMES, MIRET, MARKAL, network impact assessment model, emissions reduction cooperation model, energy techno-economic model, JRC-EU-TIMES. The coupling of PE and LCA, therefore, takes the advantage of available data of energy system modelling tools.

PEM and LCA models can be coupled following these steps:

- $\quad$ Run the PE model to obtain the marginal data, and;

- Run the LCA model to quantify the environmental impacts related to the changes in the product system.

As the two models of PEM and LCA are run independently, it is time consuming and costly to match PEM results and LCA. There may be an incompatibility between outputs of PEM and life cycle inventory databases, for example marginal products obtained by PEM are not directly matched with Ecoinvent-the most common life cycle inventory database [41]. At the same time, the independence of the two models also requires each PE model for every LCA [53]. In spite of these limitations, it is 
possible to match the outputs of PE and life cycle inventory database. The outputs of PEM include marginal technologies and energy production which are used as the inputs of energy consumption in LCA model.

The coupling of PEM and LCA offers the efficient modelling of consequential effects based on economic indicators. It can model indirect environmental impacts due to simple changes in supply, demand and price [43]. Eriksson et al. compared five combined heat and power technologies based on waste incineration and combustion of biomass or natural gas in Sweden. At a different fuel price, there is a change in the marginal electricity production and consumption (coal based or renewables based), and consequently in the technologies' environmental profiles [53]. Pehnt et al. analyzed potential $\mathrm{CO}_{2}$ reduction of offshore wind power. At different certificate price, the operation and expansion of the electricity mix of renewable and conventional power plants was altered, which consequently changed the net $\mathrm{CO}_{2}$ reduction of offshore wind power [44]. Escobar et al. combined PE and LCA to determine the feedstock combination for domestic biodiesel production in Spain and quantified its associated impacts. The PEM was used to predict the optimal feedstock mix based on farmers and biodiesel plant owners' welfare. Depending on the types and origins of the feedstock mix, the GHG savings of biodiesel were altered [58].

The coupling of PEM and LCA offers a detailed assessment of a specific product. Therefore, CLCA of one product cannot be applied to other similar products. Eriksson et al. and Pizarro-Alonso et al. applied PE and LCA in waste-based energy generation in Nordic countries and in Denmark, respectively [52,53]. These two studies applied the same methodology on the same product system in a similar context. Therefore, a similarity between these studies was expected. However, the results, in fact, convey two different results. In Eriksson et al.'s study, the results showed that waste incineration is better than landfill, but worse than recycling. On the other hand, Pizarro-Alonso et al.'s study showed climate benefits of waste trade at present as well as in the long term. The only similarity in the two studies' results is that the environmental benefits of waste-based energy generation are sensitive to waste management approaches (landfill or recycle) and energy policy (energy importing/exporting countries, marginal electricity mix), which were in fact determined by simulations of PEM for energy system development and waste management systems.

\subsection{General Equilibrium Model}

\subsubsection{Conceptual Model}

The GE model explains the behavior of supply and demand of the product system in the economy as a whole. It considers the supply, demand and price of the product system in relation to those of other economic sectors. GE expands the modelling to indirect effects of economic disturbances of different sectors on the market on the studied system [39,42,43].

Similar to PEM, there are three types of endogenous variables in the GE: Supplies, demands and prices, which are determined by the solution of the model (see Equations (4)-(6)). There are also several coefficients or parameters that reflect the reactions of demands and supplies of the commodities to the prices. For the solutions of the model at equilibrium, the prices would satisfy the requirement that the demand equals the supply of all markets for different commodities, simultaneously.

The mathematical equations for GE are presented as follows:

$$
\begin{gathered}
Q_{i, d}=Q_{i, s} \\
Q_{i, d}=a_{1, \ldots, n}-b_{1, \ldots, n} P_{1, \ldots, n} \\
Q_{i, s}=c_{1, \ldots, n} P_{1, \ldots, n}-d_{1, \ldots, n}
\end{gathered}
$$

in which:

$Q_{i, d}$ are the quantities demanded of the commodities;

$Q_{i, s}$ are the quantities supplied of the commodities; 
$P_{1, \ldots, i}$ are the prices of commodities;

$i$ are the commodities, ranging from 1 to $n$;

$a, b, c, d$ are fixed constants parameters of the economy and commodities, which can be altered depending on the specific GE modelling tool.

\subsubsection{Operational Model}

The GE model (and its variant Global Trade Analysis Project (GTAP)) was coupled with LCA to assess the indirect environmental impacts in relation with market or policy changes in the whole economy. For example, Dandres et al. quantified potential global environmental impacts on human health, global warming, natural resources and ecosystems due to changes in the EU's bioenergy policy and bioenergy generation, respectively $[63,64]$. Oladosu studied the impacts of increased bioenergy use in the US on global GHG emissions [65]. Dunn et al. evaluated global GHG emissions due to land use change for bioethanol in the US [66]. Other authors even combined several economic models of GE, PEM and IO with LCA, for example, Igos et al. evaluated the EU's GHG emissions according to the energy policy of Luxemburg [38]; or Some et al. studied changes in the bioenergy policy of the US and the EU, and its implication on global GHG emissions [21].

The GE model considers the product system in relation to the whole economy, as a result, the coupling of GE and LCA covers a large number of sectors and includes several regions. All reviewed case studies cover several economic sectors and regions, specifically 20 economic sectors in 13 regions [63,64], 33 economic sectors in 18 regions [65], 16 economic sectors in Luxembourg [38]. Apart from one case study being conducted at the national level to quantify regional impacts [38], the remaining six case studies applied GE and LCA to assess the global environmental impacts due to changes at the national level [21,63-67].

The coupling of GE and LCA shows the highest effectiveness in the medium to long term studies. All reviewed case studies were conducted for at least 15 years and up to a 30 year horizon, for example 15 years from 2006 to 2020 [21], 25 years from 2005 to 2030 [38], policy by 2030 with GTAP running from 2005 to 2010 [63], 20 years from 2005 to 2025, with GTAP running in 5 year steps [64], policy by 2030 and GE running from 2001 to 2010 [65], and by 2040 [66]. There is no study applying GE and LCA for modelling short term changes, for example several years of crop cycle or hourly/daily power/heat generation, which can be observed in studies combining PEM and LCA.

The coupling of GE and LCA provides comprehensive outputs thanks to dealing with indirect environmental effects due to change in supply, demand, price of product systems in different economic sectors. GE-LCA allows significant changes affecting large systems with a global modelling of economy to be studied [64]. It extends the modelling to off-site effects of other economic sectors on the studied product system [43]. Dandres et al. compared the results of PEM and GE based CLCA on bioenergy policy and identified that while the indirect environmental impacts of bioenergy policy are insignificant, when being quantified with PEM based CLCA, they constitute the main part of the total environmental impacts in the GE based CLCA approach [63]. Due to the improved modelling of interactions among economic sectors, the GE and LCA coupling is deemed to perform better in quantifying indirect impacts.

GE and LCA are coupled by running a GE model (mostly Global Trade Analysis Project or its variants) to predict economic disturbances caused by changes in policy or market. These disturbances will cause change in demand and production of all economic sectors. The obtained data is then mapped with inventory databases to quantify life cycle environmental impacts [64]. Due to the incompatibility between the GE results and life cycle inventory, it would require effort to combine the two databases [64]. Also, due to this incompatibility, some processes or commodities are not available in either GE or life cycle inventory, consequently, they have been excluded or other similar processes are used [64]. This causes uncertainty in the obtained results.

In order to increase the detail of the studied sector, the input data required for GE model is directly taken from PE simulation or indirectly taken from literatures which are results of PEM simulations to develop policy/market scenarios of the studied product system $[38,63,64,67]$. Therefore, it would double 
time for data collection and scenario development conducting a GE based CLCA study, compared to PEM based CLCAs. Moreover, the application of several approaches would, again, hinder uncertainty during GE and LCA coupling.

In contrast with the comprehensiveness results offered by GE based CLCA, one of its limitations is the low detail at product level. The affected products and the affected processes of the product life cycle cannot be clearly identified [5,42,43]. In GE model, each main product corresponds to one economic sector. If there is any change in the manufacturing process of the product, or any technological revolution occurring during the product's life cycle, GE models the change by reducing or increasing the commodity inputs for manufacturing that product. Therefore, in order to identify the origin of environmental impacts of the product system, several sensitivity analyses need to be conducted. For example, in order to identify whether the environmental impacts mostly come from imported or domestic commodity inputs, we need to conduct a lot of sensitivity analyses, by decreasing or increasing the value of these inputs.

At the same time, there are tens to hundreds of technologies of a product manufacturing in practice. Therefore, the technological efficiency is modelled in GE as being average in each economic sector. On the one hand, it is impossible to model the substitution effects among alternative technologies [42], for example, introducing a new technology to manufacture an existing product. On the other hand, it is impossible to trace the rebound effect of the technological efficiency [64], as technology efficiency reduces the price and increases the consumption of the product, which is in contrast with the modelling principle of GE of reducing commodity inputs in case of technological revolution.

\subsection{Input-Output Model}

\subsubsection{Conceptual Model}

The IO model describes economic flows, including production, consumption, employment and import/export, and their interrelations among different economic sectors and final users [43]. It allows the calculation of the impact for entire sectors or economy rather than focusing on specific processes [51]. It shows how parts of an economic system are affected by a change in one part of that system (the interdependency among industries) in the economy [43].

The IO model explains the relationship of the total outputs of all economic sectors and the final demand of goods and service (see Equation (7)). The technological coefficients determine the output requirements for each economic sector to satisfy the demand of goods and service. Any changes in the final demand or the technological coefficients will cause a change in the needed outputs.

IO model is based on the following equation [68]:

$$
X=(I-A)^{-1} Y
$$

in which:

$X$ is the vector of the total outputs needed to satisfy the final demand;

$Y$ is the vector of the final demand of goods and services;

$I$ is the identity matrix;

$A$ is the matrix of technological coefficients.

\subsubsection{Operational Model}

The coupling of IO (and its variant, environmental extended input-output (EEIO)) and LCA has been used to simulate the indirect impacts of changes in products' inputs and outputs of several economic sectors. Mathiesen et al. and Lund et al. coupled LCA and EnergyPLAN to identify marginal energy technologies, applied in the Danish energy system [69,70]. Cellura et al. assessed the energy and environmental impacts related to the consumption of Italian households in the period 1999-2006 and identified the economic sectors involving the highest impacts [68]. Katelhon et al. used an IO model (technology choice model) in combination with suboptimal decision and factor constraints to 
determine the marginal GHG emissions of different biomass energy technology mixes [42]. Sherwood et al. characterized the food, energy and water intensities of the US economic sector [71]. Gibon et al. assessed the human health and ecological impacts of global low carbon electricity over its life cycle [20].

The coupling of IO and LCA provides a comprehensive presentation of the economy, covering 50 industries in all economic sectors in a large geographical coverage [43], or up to 428 sectors [71]. It was also applied at global scale [20]. However, in Katelhon et al.'s study, IO-LCA was used to capture a part of the economy, with narrow spatial boundary, which assessed the thermal generation and climate change impact in a hypothetical rice plant in a province of Pakistan [42].

Similar to PE based CLCA, the coupling of IO and LCA was either applied for a short-term horizon $[69,70]$, with hourly change in the energy system, or for long term effects of technological or policy changes $[20,21,72]$. The IO-LCA does not consider time series, it normally accounts for the impacts at a static time $[34,60,61]$.

As IO is based on data of all economic sectors of a country/region(s), the coupling of IO and LCA may take advantage of public data, such as from the World Input-Output Database [73], to develop an IO table [68]. The IO model also shares the similar computational framework with LCA [71], so it requires less effort to collect the data as well as running the model. However, there is a disagreement in the literature on the requirement of data for the IO and LCA coupling. According to Katelhon et al., IO-LCA requires more data than PE/GE-LCA [42].

The coupling of IO and LCA shows its effectiveness, also in modelling both direct and indirect environmental impacts of a product system due to changes in other product systems. The modelled consequential effects include both simple, direct and off-site impacts of the economy thanks to the exhaustive background modelling [43-68]. The case study of Some et al. also showed that the coupling of GE, IO and LCA enables a broader consideration for environmental effects of biofuel policies than conventional LCA [21].

One limitation of IO-LCA is that it is based on fixed price. In other words, the changes in demand or supply of the product are independent from its price. In order to model the interaction of price, Lund et al. developed two scenarios of open and closed electricity market [69]. In open markets, the model considers the connection of the studied energy system with regional grid, and the electricity price is affected by the fluctuation in the regional grid market. In the closed market, electricity prices are determined by the production costs of the marginal production unit at the given hour. These two scenarios of price, together with technical constraints and optimized operational cost, were put into IO based CLCA to calculate the hourly marginal electricity and heat production unit to meet the demand [69].

Similar to GE based LCA, the IO and LCA coupling is criticized for its lack of detail at product level. It assumes that there is only one product per one industry, consequently the process is not fully described [71]. Therefore, technology revolution in the IO-LCA is modelled to be unchanged. Only in McDowall et al.'s study, apart from the scenario of no technology change, the authors considered change in the process in response to decarbonization policies [72]. As the authors combined PE, IO and LCA, they can take advantage of the PE model simulations of the decarbonization rate of the industry sectors producing energy technologies.

Interestingly, the study of Katelhon et al. proved that the coupling of IO and LCA can provide details at the technology level [42]. They applied an IO model to determine the marginal GHG emissions of different biomass energy technology mixes. The IO model allowed one product to be produced by several technologies, without considering the cost factor. The technology mixes are determined by factor constraints such as demand and natural resource, and inclusion of sub-optimal decision on optimized cost pathway. The six scenarios of technological mixes utilized engineering level data, and therefore provided high level of technological/sectorial detail [42].

\subsection{Dynamic Modelling}

In terms of the conceptual model, the coupling of dynamic modelling and LCA has been used to assess the impacts of dynamic interactions of a product system over its life cycle. The common 
dynamic models include ABM and SD. ABM simulates the effects of one agent on the system, while SD considers different agents' interaction within the system as a whole.

Specifically, in the energy sector, the ABM and LCA have been coupled to assess the life cycle environmental impacts of dynamic product system. Specifically, Davis et al. computed the contribution of energy technologies to global warming in the case that a policy on carbon tax is implied, while considering the demand, supply and profit of the technologies [74]. Miller et al. proposed a framework of ABM and LCA to understand the development of renewable energy technology for 20 years using Bayesian probabilities [75]. Florent and Benetto assessed environmental impacts of electric vehicles under different mobility policies in Luxembourg between 2013 and 2020 [76].

SD and LCA have been coupled to understand the impacts of the product under the systematic and dynamic interactions over time. Onat et al. assessed the life cycle sustainability of conventional, electric, hybrid and plug-in hybrid vehicles in the US from 2015 to 2050, in which seven sustainability impact categories were dynamically quantified [77].

The review indicates that the coupling of dynamic model and LCA is applied for one sector. This coincides with Beaussier et al.'s study, which clarified that ABM-LCA was frequently used for one (or several) product(s) of one sector [43], with one product in [74,75,78,79] and four products in [76,77].

The coupling of dynamic model and LCA shows its effectiveness in modelling changes in the medium to long term. The changes of the product system are modelled for 8 to 40 years [75-78]. Interestingly, the dynamic model and LCA coupling offers the simulation for time serial, for example one year steps of product/technology evolution [75,78].

The combination of dynamic model and LCA performs well in modelling the technological change at the very micro level, but can also model the sector interactions at the very macro level. At the technological level, some authors applied ABM and LCA to evaluate environmental impacts of an emerging technology. Miller et al. modelled the technology producing bioenergy from switch grass in the US, in which the adoption of technology is analyzed under behavior agents of individual resistance to change, profitability and familiarity on land adoption for biomass based energy [75]. In Florent and Benetto's study, the environmental impacts of four different types of electric cars were modelled with the decisional agents based on types of car, segment, consumption weight, travelling distance, and selling of car during the use phase under four policy scenarios [76].

At the macro level, Onat et al. applied the SD-LCA to model the life cycle impacts of four different types of US vehicles in relation to the three pillars of sustainability: Economy, environment and society [77]. The modelling, therefore, provides a comprehensive view on sustainability of the US transport system [77].

The coupling of dynamic model and LCA works with socio-economic data. On the one hand, it would be problematic to collect the specific behavior and socio economic data, which sometimes is unavailable $[75,76]$. Moreover, it causes a great deal of uncertainty due to the availability of data, and dependence on the scenario and hypothesis [75-77]. This limitation, consequently, makes it a predictive approach of forecasting how the change will occur more than for accounting purpose.

On the other hand, it performs well in modelling detailed systems with complex social economic consequential effects, which is great in assessing sustainability over a product life cycle. In fact, the coupling of the dynamic model and LCA is the only combination that can model the social impacts such as employment, public welfare, human health [77] and social behavior such as farmers/producers' $[74,75,78]$ and consumers' decision $[76,77]$. As a result, it is suited to the problems that are not totally driven by economic terms, but also driven by social behavior.

\subsection{Comparison of Modelling Tools}

The PEM explains the behavior of supply and demand of the product system as one part of the economy, which makes it a suitable tool to estimate indirect environmental impacts originating from market force when being coupled with CLCA. The coupling of PEM and LCA is frequently applied to an industry or an economic sector to model changes at the macro level, at the national or even global scale. The coupling of PEM and LCA can perform well in various time horizon, from a very short time 
frame to a long term period. Although it is simple to conduct PEM based CLCA, it cannot provide the technology or process details. The availability of PEM for the energy sector, and its relevant input data for running the PEM make it the most frequently used in coupling with LCA for quantifying both direct and indirect environmental impacts of the energy sector. Although there are complaints on the incompatibility between PE and LCA, it is possible to match the two approaches.

The GE model explains the behavior of supply and demand of the product system in the economy as a whole, which makes the coupling of GE and LCA perform well in modelling indirect environmental impacts in relation with market and policy changes in the whole economy. The coupling of GE and LCA is suitable to model several economic sectors in a large number of regions, and it has shown to be most effective for modelling medium to long term change. Therefore, it provides a comprehensive view of the product system in relation to the economy. Compared to PE, GE requires more time for collecting data and matching the obtained results to LCA model. Furthermore, its limitation lies in the incapability of modelling details at product level.

The IO model describes the economic flows of different sectors in the society, therefore, the coupling of IO and LCA can be applied to model indirect impacts of changes in product inputs and outputs in several economic sectors. The coupling of IO and LCA can cover all economic sectors in a large geographical boundary. It can be applied for short term to long term horizons. Its strength lies in the effectiveness in modelling indirect impacts of a product system due to change in other systems, with the availability of a public IO database and a similar framework to LCA. Its limits are in the modelling principle of independence from price and lack of detail at the product level. However, some exceptional examples from the review indicate the application of IO based CLCA for modelling causal relationship of price and product system, as well as providing the product details.

The dynamic model simulates the effects of one agent on the system (ABM) or considers different agents' interaction in the system as a whole (SD). The coupling of ABM and LCA is used to model environmental impacts of a dynamic product system, for example, innovative technology, while the SD and LCA coupling is applied to understand the impacts of the products under complex systematic and dynamic interactions over time. The dynamic model and LCA coupling normally covers one economic sector, and a medium to long term horizon. The coupling of the dynamic model and LCA performs well in modelling technological change at very micro levels, and sector interactions at macro levels. Although it is quite complex to conduct a CLCA based on a dynamic model, the coupling shows to be the most effective in modelling socio-economic indicators and offering diversified outputs of both quantitative and qualitative indicators of sustainability.

With the application of different modelling tools for CLCA, it is expected that there will be a difference in the obtained results. For example, Dandres et al. assessed the bioenergy policy in the EU with PEM and GE, and identified that with the application of PEM based LCA, the global warming impacts are smaller compared to those obtained with GE based LCA. With the application of GE, and the inclusion of economic evolution, the potential impacts from China as an emerging market, caused a huge increase in the total global warming impact. For example, the potential life cycle impact of EU bioenergy policy in/from China is around $5 \times 10^{9} \mathrm{kgCO}_{2} \mathrm{e}$ with PEM based LCA, while this number is $2.5 \times 10^{12} \mathrm{kgCO}_{2} \mathrm{e}$ with GE based LCA [64]. This also happened to other markets such as South Asia, North America, Middle East and North Africa, etc., and other environmental impact categories such as human health, ecosystems and natural resources [64].

Regardless of the used model, it is important to highlight that LCA studies generally have an intrinsic uncertainty related to various factors (i.e., difficulty in the survey of data, lack of detailed information sources, data quality, etc.) [80]. Thus, transparency of the studies and the use of sensitivity analysis are paramount for improving the reliability of the results [81].

A summary of the different models for CLCA is presented in Table 1. 
Table 1. Features of the models for consequential life cycle assessment (CLCA).

\begin{tabular}{|c|c|c|c|c|c|}
\hline & PEM + LCA & GE + LCA & IO + LCA & $\mathrm{ABM}+\mathrm{LCA}$ & SD + LCA \\
\hline Application & $\begin{array}{l}\text { Apply for changes } \\
\text { originating from market } \\
\text { force, with disregard of the } \\
\text { whole economy } \\
\text { - One industry or } \\
\text {-economic sector } \\
\text { - Various time horizon }\end{array}$ & $\begin{array}{l}\text { Apply for changes } \\
\text { originating from market } \\
\text { force, with regard to the } \\
\text { whole economy } \\
\text { - } \quad \text { All economic sectors } \\
\text { - }\end{array}$ & $\begin{array}{ll}\text { - } & \text { Apply for changes } \\
\text { due to } \\
\text { economic interactions } \\
\text { - } \quad \text { All economic sectors } \\
\text { - } \quad \text { Various } \\
\text { time horizon }\end{array}$ & $\begin{array}{ll}\text { - } & \text { Apply to changes of one } \\
\text { agent in } \\
\text { socio-economic context } \\
\text { - } & \text { One economic sector } \\
\text { - } & \text { Medium to long term }\end{array}$ & $\begin{array}{l}\text { Apply to changes of the } \\
\text { whole system in } \\
\text { socio-economic context } \\
\text { - } \quad \text { One economic sector } \\
\text { - } \quad \text { Medium to long term }\end{array}$ \\
\hline Input data & $\begin{array}{l}\text { Price, demand of the studied } \\
\text { product system, consumption of } \\
\text { environmental inflows, } \\
\text { emission factors }\end{array}$ & $\begin{array}{l}\text { Price, demand of all commodities, } \\
\text { consumption of environmental } \\
\text { inflows, emission factors }\end{array}$ & $\begin{array}{l}\text { Inputs, outputs of goods } \\
\text { and services, } \\
\text { consumption of } \\
\text { environmental inflows, } \\
\text { emission factors }\end{array}$ & $\begin{array}{l}\text { Cost, consumption pattern of the } \\
\text { studied product system, } \\
\text { environmental inflows, } \\
\text { emission factors }\end{array}$ & $\begin{array}{l}\text { Cost, consumption pattern of the } \\
\text { studied product system, } \\
\text { environmental inflows, emission } \\
\text { factors }\end{array}$ \\
\hline Obtained results & $\begin{array}{l}\text { - Environmental and economi } \\
\text { E.g., change in GHG emissions (tC } \\
\text { over time due to increased bioene } \\
\text { Change in natural resource deplet } \\
\text { (at an equilibrium power price) du } \\
\text { Change in climate change impact } \\
2030 \text { (at a carbon price) due to pol }\end{array}$ & $\begin{array}{l}\text { indicators (quantitative) } \\
\mathrm{O}_{2} \mathrm{e} \text { ) and animal feed supply and de } \\
\mathrm{gy} \text { demand or power production. } \\
\text { on (kg of used metal) and generation } \\
\mathrm{e} \text { to increase in solar PV capacity ano } \\
\mathrm{CO}_{2} \mathrm{e} \text { ) and power production and st } \\
\mathrm{cy} \text { on renewable portfolio standard. }\end{array}$ & $\begin{array}{l}\text { mand (ton of animal feed) } \\
\text { of different types of power } \\
\text { Igeneration. } \\
\text { ructure of power system by }\end{array}$ & $\begin{array}{l}\text { Environmental and socio-eco } \\
\text { and qualitative) } \\
\text { E.g., changing land patterns for en } \\
\text { in bioenergy demand; changing ar } \\
\text { to change in farmer behavior. } \\
\text { Dynamics of annual human health } \\
\text { due to application of an energy po } \\
\text { Reduction in indirect cost (million } \\
\text { to implementation of Paris Agreen }\end{array}$ & $\begin{array}{l}\text { nomic indicators (quantitative } \\
\text { ergy crops over time due to change } \\
\text { ea of land for energy crops (ha) due } \\
\text { impacts for } 20 \text { year period (DALY) } \\
\text { licy. } \\
\text { USD) of electricity generation due } \\
\text { lent }\end{array}$ \\
\hline Strengths & $\begin{array}{ll}\text { - } & \text { Availability of data and } \\
\text { energy development model } \\
\text { - } & \text { Provides product detail }\end{array}$ & $\begin{array}{l}\text { Availability of data and } \\
\text { global trade model }\end{array}$ & $\begin{array}{ll}\text { - } & \text { Availability of } \\
\text { public database } \\
\text { - } \\
\text { Shares a similar } \\
\text { framework } \\
\text { with LCA }\end{array}$ & $\begin{array}{ll}\text { - } & \text { Good at modelling } \\
\text { technological changes at } \\
\text { micro level } \\
\text { Ability to work with } \\
\text { socio-economic data }\end{array}$ & $\begin{array}{l}\text { - } \quad \text { Good at modelling } \\
\text { technological changes at } \\
\text { macro level } \\
\text { Ability to work with } \\
\text { socio-economic data }\end{array}$ \\
\hline Limitations & $\begin{array}{l}\text { Incompatibility between } \\
\text { PEM and LCA, but not too } \\
\text { difficult to match } \\
\text { two models }\end{array}$ & 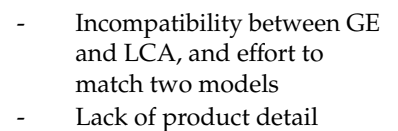 & $\begin{array}{ll}- & \text { Price independence } \\
- & \text { Lack of } \\
\text { product detail }\end{array}$ & $\begin{array}{l}\text { Difficult to collect data and } \\
\text { complex to run the model }\end{array}$ & $\begin{array}{l}\text { - Difficult to collect data and } \\
\text { complex to run the model }\end{array}$ \\
\hline
\end{tabular}




\section{Conclusions}

In summary, the coupling of economic models and life cycle assessments quantifies both direct and indirect environmental impacts of a product system to the extent of change in the technological development and socio-economic context. During the period of 2006-2020, the commonly used economic models include partial equilibrium, general equilibrium, input-output, agent based modelling and system dynamics, in which the coupling of partial equilibrium and life cycle assessment is the most frequent combination. There is a trend in combining several economic models such as partial and general equilibrium, partial equilibrium and input-output, and general equilibrium and input-output with life cycle assessment to make each economic modelling tool the most effective.

The coupling of partial or general equilibrium and life cycle assessment estimates environmental impacts from the changes due to the market mechanism, with some strengths on the availability of modelling tools and relevant input data. Partial or general equilibrium and life cycle assessment models are inharmonious in their databases and modelling approaches. It is not too difficult to match partial equilibrium and life cycle assessment, while it takes some effort to match general equilibrium and life cycle assessment. The coupling of input-output and life cycle assessment works well in modelling environmental impacts induced from economic changes thanks to availability of public input-output databases and similar frameworks with life cycle assessment. However, the input-output and life cycle assessment coupling simulates the change with independence from price and lack of product details. The dynamic model and life cycle assessment combination simulate the social and environmental impacts, but running a dynamic model is complex and takes a lot of effort for collecting input data for the models. As a result, the choice of using one or more economic models combined with life cycle assessment may be determined by the goal of the study, the nature of the changes due to market mechanisms, economic or social origins, and the availability of data.

Author Contributions: All authors contributed to the paper development and writing. Conceptualization, Q.L.L. and S.L.; methodology, E.R.S. and M.C.; formal analysis, Q.L.L. and M.A.C.; investigation, Q.L.L. and V.F.; writing —original draft preparation, Q.L.L.; writing—review and editing, S.L. and M.A.C.; visualization, E.R.S. and M.C.; supervision, E.R.S., M.C. and V.F. All authors have read and agreed to the published version of the manuscript.

Conflicts of Interest: The authors declare no conflict of interest.

\section{References}

1. Mandl, N.; Pinterits, M.; Anderson, G.; Burgstaller, J.; Carmona, G.; Danila, A.; Emele, L. Annual European Union Greenhouse Gas Inventory 1990-2016 and Inventory Report; European Environment Agency: Copenhagen, Denmark, 2008.

2. Horne, R.E. Life cycle assessment: Origins, principles and context. In Life Cycle Assessment-Principles, Practice and Prospects; Horne, R.E., Tim, G., Karli, V., Eds.; CSIRO Publishing: Clayton, Australia, 2009.

3. Georgescu-Roegen, N. The Entropy Law and the Economic Process; Harvard University Press: Cambridge, MA, USA, 1971.

4. UNSTATS. The System of National Accounts (SNA); European Communities; International Monetary Fund; Organisation for Economic Co-operation and Development; United Nations; World Bank: New York, NY, USA, 2009.

5. Ekvall, T. Cleaner production tools: LCA and beyond. J. Clean. Prod. 2002, 10, 403-406. [CrossRef]

6. Ekvall, T.; Weidema, B.P. System boundaries and input data in consequential life cycle inventory analysis. Int. J. Life Cycle Assess. 2004, 9, 161-171. [CrossRef]

7. Curran, M.A.; Mann, M.; Norris, G. The international workshop on electricity data for life cycle inventories. J. Clean. Prod. 2005, 12, 853-862. [CrossRef]

8. Georgescu-Roegen, N. Dynamic models and economic growth. World Dev. 1975, 3, 765-783. [CrossRef]

9. Soimakallio, S.; Kiviluoma, J.; Saikku, L. The complexity and challenges of determining GHG (greenhouse gas) emissions from grid electricity consumption and conservation in LCA (life cycle assessment): A methodological review. Energy 2004, 36, 6705-6713. [CrossRef] 
10. Nielsen, P.H.; Oxenboll, K.M.; Wenzel, H. Cradle-to-Gate Environmental Assessment of Enzyme Products Produced Industrially in Denmark by Novoaymes A/S. Int. J. Life Cycle Assess. 2007, 12, 432-438. [CrossRef]

11. Earles, J.M.; Halog, A. Consequential life cycle assessment: A review. Int. J. Life Cycle Assess. 2011, 16, 445-453. [CrossRef]

12. Georgescu-Roegen, N. The Entropy Law and the Economic Process in Retrospect. East. Econ. J. 1986, 12, 3-25.

13. Georgescu-Roegen, N. Energy Analysis and Economic Valuation. South. Econ. J. 1979, 45, $1023-1058$. [CrossRef]

14. Brown, M.T.; Herendeen, R.A. Embodied energy analysis and EMERGY analysis: A comparative view. Ecol. Econ. 1996, 19, 219-235. [CrossRef]

15. Schoer, K. Handbook for Estimating Raw Material Equivalents; Eurostat: Brussels, Belgium, 2019.

16. UNCEEA. System of Environmental Economic Accounting. Available online: www.seea.un.org (accessed on 6 June 2020).

17. Glasziou, P. Chapter 14 How to write a review. In How to Write a Paper; Hall, G., Ed.; John Wiley and Sons Publishing: Hoboken, NJ, USA, 2013.

18. Warner, E.S.; Heath, G.A. Life Cycle Greenhouse Gas Emissions of Nuclear Electricity Generation. J. Ind. Ecol. 2012, 16, S73-S92. [CrossRef]

19. Herbert, A.S.; Azzaro-Pantel, C.; Le Boulch, D. A typology for world electricity mix: Application for inventories in Consequential LCA (CLCA). Sustain. Prod. Consum. 2016, 8, 93-107. [CrossRef]

20. Gibon, T.; Hertwich, E.G.; Arvesen, A.; Singh, B.; Verones, F. Health benefits, ecological threats of low-carbon electricity. Environ. Res. Lett. 2017, 12, 034023. [CrossRef]

21. Some, A.; Dandres, T.; Gaudreault, C.; Majeau-Bettez, G.; Wood, R.; Samson, R. Coupling Input-Output Tables with Macro-Life Cycle Assessment to Assess Worldwide Impacts of Biofuels Transport Policies. J. Ind. Ecol. 2018, 22, 643-655. [CrossRef]

22. Vandepaer, L.; Treyer, K.; Mutel, C.; Bauer, C.; Amor, B. The integration of long-term marginal electricity supply mixes in the ecoinvent consequential database version 3.4 and examination of modeling choices. Int. J. Life Cycle Assess. 2019, 24, 1409-1428. [CrossRef]

23. Hou, J.; Zhang, W.; Wang, P.; Dou, Z.; Gao, L.; Styles, D. Greenhouse Gas Mitigation of Rural Household Biogas Systems in China: A Life Cycle Assessment. Energies 2017, 10, 239. [CrossRef]

24. Moore, C.C.S.; Nogueira, A.R.; Kulay, L. Environmental and energy assessment of the substitution of chemical fertilizers for industrial wastes of ethanol production in sugarcane cultivation in Brazil. Int. J. Life Cycle Assess. 2017, 22, 628-643. [CrossRef]

25. Brandao, M.; i Canals, L.M.; Clift, R. Soil organic carbon changes in the cultivation of energy crops: Implications for GHG balances and soil quality for use in LCA. Biomass Bioenergy 2011, 35, 2323-2336. [CrossRef]

26. Prapaspongsa, T.; Gheewala, S.H. Risks of indirect land use impacts and greenhouse gas consequences: An assessment of Thailand's bioethanol policy. J. Clean. Prod. 2016, 134, 563-573. [CrossRef]

27. Karlsson, H.; Ahlgren, S.; Strid, I.; Hansson, P.A. Faba beans for biorefinery feedstock or feed? Greenhouse gas and energy balances of different applications. Agric. Syst. 2015, 141, 138-148. [CrossRef]

28. Roux, C.; Peuportier, B. Evaluation of the environmental performance of buildings using dynamic life cycle simulation. In Proceedings of the 13th International Conference of International Building Performance Simulation Association, Chambery, France, 26-28 August 2013.

29. Roux, C.; Schalbart, P.; Peuportier, B. Development of an electricity system model allowing dynamic and marginal approaches in LCA-tested in the French context of space heating in buildings. Int. J. Life Cycle Assess. 2017, 22, 1177-1190. [CrossRef]

30. Collinge, W.O.; Rickenbacker, H.J.; Landis, A.E.; Thiel, C.L.; Bilec, M.M. Dynamic Life Cycle Assessments of a Conventional Green Building and a Net Zero Energy Building: Exploration of Static, Dynamic, Attributional, and Consequential Electricity Grid Models. Environ. Sci. Technol. 2018, 52, 11429-11438. [CrossRef]

31. Elzein, H.; Dandres, T.; Levasseur, A.; Samson, R. How can an optimized life cycle assessment method help evaluate the use phase of energy storage systems? J. Clean. Prod. 2019, 209, 1624-1636. [CrossRef]

32. Fukushima, Y.; Chen, S.P. A decision support tool for modifications in crop cultivation method based on life cycle assessment: A case study on greenhouse gas emission reduction in Taiwanese sugarcane cultivation. Int. J. Life Cycle Assess. 2009, 14, 639-655. [CrossRef] 
33. Kimming, M.; Sundberg, C.; Nordberg, A.; Baky, A.; Bernesson, S.; Noren, O.; Hansson, P.A. Life cycle assessment of energy self-sufficiency systems based on agricultural residues for organic arable farms. Bioresour. Technol. 2011, 102, 1425-1432. [CrossRef] [PubMed]

34. Kimming, M.; Sundberg, C.; Nordberg, A.; Baky, A.; Bernesson, S.; Hansson, P.A. Replacing fossil energy for organic milk production-potential biomass sources and greenhouse gas emission reductions. J. Clean. Prod. 2015, 106, 400-407. [CrossRef]

35. Styles, D.; Dominguez, E.M.; Chadwick, D. Environmental balance of the UK biogas sector: An evaluation by consequential life cycle assessment. Sci. Total Environ. 2016, 560, 241-253. [CrossRef]

36. Glogic, E.; Weyand, S.; Tsang, M.P.; Young, S.B.; Schebek, L.; Sonnemann, G. Life cycle assessment of organic photovoltaic charger use in Europe: The role of product use intensity and irradiation. J. Clean. Prod. 2019, 233, 1088-1096. [CrossRef]

37. Brander, M. Comparative analysis of attributional corporate greenhouse gas accounting, consequential life cycle assessment, and project/policy level accounting: A bioenergy case study. J. Clean. Prod. 2017, 167, 1401-1414. [CrossRef]

38. Igos, E.; Rugani, B.; Rege, S.; Benetto, E.; Drouet, L.; Zachary, D.S. Combination of equilibrium models and hybrid life cycle-input-output analysis to predict the environmental impacts of energy policy scenarios. Appl. Energy 2015, 145, 234-245. [CrossRef]

39. Vázquez-Rowe, I.; Rege, S.; Marvuglia, A.; Thenie, J.; Haurie, A.; Benetto, E. Application of three independent consequential LCA approaches to the agricultural sector in Luxembourg. Int. J. Life Cycle Assess. 2013, 18, 1593-1604. [CrossRef]

40. Ekvall, T. A market-based approach to allocation at open-loop recycling. Resour. Conserv. Recycl. 2000, 29, 91-109. [CrossRef]

41. Earles, J.M.; Halog, A.; Ince, P.; Skog, K. Integrated Economic Equilibrium and Life Cycle Assessment Modeling for Policy-based Consequential LCA. J. Ind. Ecol. 2013, 17, 375-384. [CrossRef]

42. Katelhon, A.; Bardow, A.; Suh, S.W. Stochastic technology choice model for consequential life cycle assessment. Environ. Sci. Technol. 2016, 50, 12575-12583. [CrossRef]

43. Beaussier, T.; Cairla, S.; Maurel, V.B.; Loiseau, E. Coupling economic models and environmental assessment methods to support regional policies: A critical review. J. Clean. Prod. 2019, 2016, 408-421. [CrossRef]

44. Pehnt, M.; Oeser, M.; Swider, D.J. Consequential environmental system analysis of expected offshore wind electricity production in Germany. Energy 2008, 33, 747-759. [CrossRef]

45. Choi, J.K.; Friley, P.; Alfstad, T. Implication of energy policy on a product system's dynamic life-cycle environmental impact: Survey and model. Renew. Sustain. Energy Rev. 2012, 16, 4744-4752. [CrossRef]

46. Dandres, T.; Vandromme, N.; Obrekht, G.; Wong, A.; Nguyen, K.K.; Lemieux, Y.; Cheriet, M.; Samson, R. Consequences of Future Data Center Deployment in Canada on Electricity Generation and Environmental Impacts A 2015-2030 Prospective Study. J. Ind. Ecol. 2017, 21, 1312-1322. [CrossRef]

47. Raugei, M.; Leccisi, E.; Azzopardi, B.; Jones, C.; Gilbert, P.; Zhang, L.X.; Zhou, Y.T.; Mander, S.; Mancarella, P. A multi-disciplinary analysis of UK grid mix scenarios with large-scale PV deployment. Energy Policy 2018, 114, 51-62. [CrossRef]

48. Jones, C.; Gilbert, P. Determining the consequential life cycle greenhouse gas emissions of increased rooftop photovoltaic deployment. J. Clean. Prod. 2018, 184, 211-219. [CrossRef]

49. Algunaibet, I.M.; Pozo, C.; Galan-Martin, A.; Guillen-Gosalbez, G. Quantifying the cost of leaving the Paris Agreement via the integration of life cycle assessment, energy systems modeling and monetization. Appl. Energy 2019, 242, 588-601. [CrossRef]

50. Vandepaer, L.; Cloutier, J.; Bauer, C.; Amor, B. Integrating Batteries in the Future Swiss Electricity Supply System: A Consequential Environmental Assessment. J. Ind. Ecol. 2019, 23, 709-725. [CrossRef]

51. Blanco, H.; Codina, V.; Laurent, A.; Nijs, W.; Maréchal, F.; Faaij, A. Life cycle assessment integration into energy system models: An application for Power-to-Methane in the EU. Appl. Energy 2020, 259, 114160. [CrossRef]

52. Pizarro-Alonso, A.; Cimpan, C.; Munnstr, M. The climate footprint of imports of combustible waste in systems with high shares of district heating and variable renewable energy. Waste Manag. 2018, 79, 800-814. [CrossRef]

53. Eriksson, O.; Finnveden, G.; Ekvall, T.; Bjorklund, A. Life cycle assessment of fuels for district heating: A comparison of waste incineration, biomass- and natural gas combustion. Energy Policy 2007, 35, 1346-1362. [CrossRef]

54. Rozakis, S.; Haque, M.I.; Natsis, A.; Walker, M.B.; Mizak, K. Cost effectiveness of bioethanol policies to reduct carbon dioxide emission in Greece. Int. J. Life Cycle Assess. 2013, 18, 306-318. [CrossRef] 
55. Rege, S.; Arenx, M.; Marvuglia, A.; Vazquez-Rowe, I.; Benetto, E.; Igos, E.; Koster, D. Quantification of Agricultural Land Use Changes in Cnsequential Life Cycle Assessment Using Mathematical Programming Models Following a Partial Equilibrium Approach. J. Environ. Inform. 2015, 26, 121-139.

56. Vazquez-Rowe, I.; Marvuglia, A.; Rege, S.; Benetto, E. Applying consequential LCA to support energy policy: Land use change effects of bioenergy production. Sci. Total Environ. 2014, 472, 78-89. [CrossRef] [PubMed]

57. Menten, F.; Tchung-Ming, S.; Lorne, D.; Bouvart, F. Lessons from the use of a long-term energy model for consequential life cycle assessment: The BTL case. Renew. Sustain. Energy Rev. 2015, 43, 942-960. [CrossRef]

58. Escobar, N.; Manrique-de-Lara-Penate, C.; Sanjuan, N.; Clemente, G.; Rozakis, S. An agro-industrial model for the optimization of biodiesel production in Spain to meet the European GHG reduction targets. Energy 2017, 120, 619-631. [CrossRef]

59. Tonini, D.; Vadenbo, C.; Astrup, T.F. Priority of domestic biomass resources for energy: Importance of national environmental targets in a climate perspective. Energy 2017, 124, 295-309. [CrossRef]

60. Vadenbo, C.; Tonini, D.; Astrup, T.F. Environmental Multiobjective Optimization of the Use of Biomass Resources for Energy. Environ. Sci. Technol. 2017, 51, 3575-3583. [CrossRef] [PubMed]

61. Vadenbo, C.; Tonini, D.; Burg, V.; Astrup, T.F.; Thees, O.; Hellweg, S. Environmental optimization of biomass use for energy under alternative future energy scenarios for Switzerland. Biomass Bioenergy 2018, 119, 462-472. [CrossRef]

62. Albers, A.; Collet, P.; Lorne, D.; Benoist, A.; Helias, A. Coupling partial-equilibrium and dynamic biogenic carbon models to assess future transport scenarios in France. Appl. Energy 2019, 239, 316-330. [CrossRef]

63. Dandres, T.; Gaudreault, C.; Tirado-Seco, P.; Samson, R. Macroanalysis of the economic and environmental impacts of a 2005-2025 European Union bioenergy policy using the GTAP model and life cycle assessment. Renew. Sustain. Energy Rev. 2012, 16, 1180-1192. [CrossRef]

64. Dandres, T.; Gaudreault, C.; Tirado-Seco, P.; Samson, R. Assessing non-marginal variations with consequential LCA: Application to European energy sector. Renew. Sustain. Energy Rev. 2011, 15, 3121-3132. [CrossRef]

65. Oladosu, G. Estimated of the global indirect energy-use emission impacts of USA biofuel policy. Appl. Energy 2012, 99, 85-96. [CrossRef]

66. Dunn, J.B.; Mueller, S.; Kwon, H.Y.; Wang, M.Q. Land use change and green house gas emissions from corn and cellulosic ethanol. Biotechnol. Biofuels 2013, 6, 1-13. [CrossRef]

67. Marvuglia, A.; Benetto, E.; Rege, S.; Jury, C. Modelling approaches for consequential life-cycle assessment (C-LCA) of bioenergy: Critical review and proposed framework for biogas production. Renew. Sustain. Energy Rev. 2013, 25, 768-781. [CrossRef]

68. Cellura, M.; Longo, S.; Mistretta, M. The energy and environmental impacts of Italian households consumptions: An input output approach. Renew. Sustain. Energy Rev. 2011, 15, 3897-3908. [CrossRef]

69. Sherwood, J.; Clabeaux, R.; Carbajales-Dale, M. An extended environmental input-output lifecycle assessment model to study the urban food-energy-water nexus. Environ. Res. Lett. 2017, 12, 105003. [CrossRef]

70. Mathiesen, B.V.; Munster, M.; Fruergaard, T. Uncertainties related to the identification of the marginal energy technology in consequential life cycle assessments. J. Clean. Prod. 2009, 17, 1331-1338. [CrossRef]

71. Lund, H.; Mathiesen, B.V.; Christensen, P.; Schmidt, J.H. Energy system analysis of marginal electricity supply in consequential LCA. Int. J. Life Cycle Assess. 2010, 15, 260-271. [CrossRef]

72. McDowall, W.; Rodriguez, B.S.; Usubiaga, A.; Fernandez, J.A. Is the optimal decarbonization pathway influenced by indirect emissions? Incorporating indirect life-cycle carbon dioxide emissions into a European TIMES model. J. Clean. Prod. 2018, 170, 260-268. [CrossRef]

73. Timmer, M.P.; Dietzenbacher, E.; Los, B.; Stehrer, R.; de Vries, G.J. An Illustrated User Guide to the World Input-Output Database: The Case of Global Automotive Production. Rev. Int. Econ. 2015, 23, 575-605. [CrossRef]

74. Davis, C.; Nikolic, I.; Dijkema, G.P.J. Intergration of life cycle assessment into agent based modeling Toward informed decisions on evolving infrastructure systems. J. Ind. Ecol. 2009, 13, 306-325. [CrossRef]

75. Miller, S.A.; Moysey, S.; Sharp, B.; Alfaro, J. A Stochastic Approach to Model Dynamic Systems in Life Cycle Assessment. J. Ind. Ecol. 2012, 17, 352-362. [CrossRef]

76. Florent, Q.; Enrico, B. Combining Agent Based Modeling and Life Cycle Assessment for the Evaluation of Mobility Policies. Environ. Sci. Technol. 2015, 49, 1744-1751. [CrossRef] 
77. Onat, N.C.; Kucukvar, M.; Tatari, O. Uncertainty-embedded dynamic life cycle sustainability assessment framework: An ex-ante perpective on the impacts of alternative vehicle options. Energy 2016, 112, 715-728. [CrossRef]

78. Marvuglia, A.; Rege, S.; Gutierrez, T.N.; Vanni, L.; Stilmant, D.; Benetto, E. A return on experience from the application of agent based simulations coupled with life cycle assessment to model agricultural process. J. Clean. Prod. 2017, 142, 1539-1551. [CrossRef]

79. Zhao, G.; Guerrero, J.M.; Pei, Y. Marginal Generation Technology in the Chinese Power Market towards 2030 Based on Consequential Life Cycle Assessment. Energies 2016, 9, 788. [CrossRef]

80. Ardente, F.; Beccali, M.; Cellura, M. FALCADE: A fuzzy software for the energy and environmental balances of products. Ecol. Model. 2004, 176, 359-379. [CrossRef]

81. Ardente, F.; Beccali, G.; Cellura, M. Eco-sustainable energy and environmental strategies in design for recycling: The software “ENDLESS". Ecol. Model. 2003, 163, 101-118. [CrossRef]

(C) 2020 by the authors. Licensee MDPI, Basel, Switzerland. This article is an open access article distributed under the terms and conditions of the Creative Commons Attribution (CC BY) license (http://creativecommons.org/licenses/by/4.0/). 